\title{
Modos de vida e identidade em blogs de pessoas com deficiência
}

\section{Lifestyle and identity in blogs of people with disabilities}

\begin{abstract}
Resumo: A internet tem se consolidado com uma esfera de produção e divulgação cultural bastante interessante e profícua ao debate acadêmico. Este estudo analisa 14 blogs criados e mantidos por pessoas com deficiência, caracterizando seus principais assuntos e a forma como abordam a temática da deficiência. O objetivo é avaliar as perspectivas presentes nos discursos em torno da deficiência à luz do modelo social. Para tanto, utiliza-se como método a netnografia, como forma de aproximação e análise dos textos publicados nos blogs, os quais são classificados em três categorias de análise: o bom humor, afetividade/sexualidade e informação/direitos humanos. Conclui-se esse estudo apontando para a emergência de novas narrativas sobre a deficiência na internet que fogem à lógica medicalizante e buscam dar visibilidade às barreiras sociais que incidem na vida das pessoas que possuem impedimentos ou lesões de natureza física, produzindo identidades.

Palavras-chave: Deficiência. Netnografia. Identidade.
\end{abstract}

Abstract: The Internet has become asserting its position as a sphere of cultural production and dissemination that is quite interesting and useful to the academic debate. This study analyzes 14 blogs created and maintained by people with disabilities, identifying their main topics and how they address disability issues. Our aim is to evaluate the prospects of the discourse around disability in the light of the social model. For this purpose, it shall be used the method of netnography as an approximation and analysis of texts published in blogs, which are classified into three categories of analysis: humor, affection/sexuality, and information/human rights. We conclude this study pointing to the emergence of new narratives on disability on the Internet that are beyond the medicalized logic and seek to highlight the social barriers that affect the lives of people who have impairments or injury of a physical nature, producing identities.

Keywords: Disabilities. Virtual Ethnography. Identity.

LUIZ, Karla G.; NUERNBERG, Adriano H. Modos de vida e identidade em blogs de pessoas com d eficiência. Informática na Educação: teoria e prática, Porto Alegre, v. 16, n. 1, p. 191-205, jan./jun. 2013.

\section{Karla Garcia Luiz \\ Adriano Henrique Nuernberg \\ Universidade Federal de Santa Catarina}

\section{Modos de vida e identidade em blogs de pessoas com deficiência}

D urante a maior parte da história ocidental as pessoas com deficiência foram abordadas como objetos, tendo seus corpos e funções definidas, classificadas e dispostas em racionalidades míticas ou medicalizantes que restringiam suas possibilidades de existência e inserção social (LOBO, 2008). É vasto o material bibliográfico que analisa esse processo e que aponta para a legitimação religiosa ou científica da exclusão e segregação dessas pessoas (BARNES; OLIVER; BARTON, 2008; OLKIN, 1999). Baseando-se em noções que consideram a vida com deficiência como uma tragédia pessoal e que reduzem essas pessoas à sua lesão ou patologia, tais modelos de compreensão dessa condição não conferem a estas pessoas o estatuto de pessoas comuns, elimi- 
nando a singularidade como atributo inerente a sua condição humana (DINIZ, 2007; 2010).

Ainda que se perpetuem essas perspectivas excludentes e que a realidade das pessoas com deficiência prossiga sendo marcada pelo isolamento e pela negação de seus direitos humanos, podemos dizer que uma série de avanços está ocorrendo em relação ao acesso e participação social, o que se reflete no maior protagonismo destas pessoas sobre suas vidas nas diferentes esferas de atuação no espaço público e privado. A difusão dos princípios inclusivos na educação e no mundo trabalho e a consolidação de uma série de documentos, Convenções e tratados que legitimam os direitos civis das pessoas com deficiência são as maiores evidências dessas transformações, as quais não podem ser outra coisa senão o resultado das lutas e movimentos sociais engendradas pelas próprias pessoas com deficiência e seus representantes, familiares e simpatizantes (DINIZ; MEDEIROS; BARBOSA, 2010).

Esse processo vem se refletindo na maior presença das pessoas em todos os contextos sociais, fazendo emergir uma realidade que até então vinha sendo relegada ao discurso médico-terapêutico, psicológico e pedagógico. Mesmo no contexto acadêmico, onde a deficiência sempre foi um tema das ciências da saúde e da educação, começa-se agora a testemunhar a emergência de novos campos, como a sociologia e a antropologia da deficiência, em áreas do conhecimento científico que negligenciavam esse tema por não se reconhecerem nele, justamente pelo enorme peso histórico da medicalização da deficiência (LEVIN ROJO; ESPINOZA, 2009).

Interessa nesse texto analisar a presença de novos discursos em torno da deficiência, produzidos por quem vive essa condição e que são difundidos por meio de veículos mediados pela internet. Tais discursos vem à reboque dessas transformações e representam ao mesmo tempo um produto engendrado pelas atuais formas de comunicação e organização social, que utilizam de novas tecnologias e mídias, como também resultam da melhoria das condições de existência e participação social das pessoas com deficiência. Para tanto, são analisados 14 blogs criados e mantidos por pessoas com deficiência e que possuem uma relativa expressão na internet, caracterizando seus principais assuntos e a forma como abordam a temática da deficiência, problematizando a produção da identidade pessoal e coletiva.

Com base no modelo social da deficiência (DINIZ, 2007; BARNES et al., 2008), são identificados enunciados, acontecimentos e perspectivas que tensionam noções que circulam no senso comum sobre essa condição, produzindo novos sentidos sobre essa realidade a partir da expressão de quem vivencia no cotidiano a experiência da deficiência.

\section{0 modelo social da deficiência}

A opção pelo modelo social da deficiência como perspectiva de análise se assenta em sua abertura à reflexão sobre as transformações da deficiência como categoria social. Esse modelo surgiu na década de 60 no Reino Unido, a partir da reação de movimentos sociais de pessoas com deficiência que reivindicavam a redefinição da deficiência como um fato que não se restringia à lesão. Seu argumento inaugural é o de que a deficiência é um produto da opressão social, que impõe barreiras à participação destas pessoas na sociedade.

Para Diniz (2007), no modelo social a deficiência deixa de ser uma "tragédia pessoal" causada pela "Ioteria da natureza" para ser um 
problema de ordem social e cultural. Nessa lógica, o foco de ação deixa de ser centrado no sujeito para se concentrar no contexto, mais precisamente, nas barreiras que restringem a mobilidade, a comunicação, o acesso à informação e a participação social. Assim, a deficiência deixa de ser um problema exclusivamente médico para ser um problema econômico, social, arquitetônico, de direitos humanos, cultural.

O modelo social da deficiência é hoje uma das principais referências do campo de estudos sobre deficiência, bastante difundido nos países de língua inglesa, mas ainda pouco conhecido em nosso país como um campo científico. De natureza interdisciplinar, esse campo procura analisar diferentes aspectos da experiência da deficiência sob a ótica das ciências sociais.

Conforme Diniz (2007), a primeira geração dos estudos sobre deficiência alargou o conceito de deficiência e recolocou esse tema para além do discurso biomédico. Já a segunda geração dos estudos sobre deficiência é marcada pela influência dos estudos feministas, revendo a premissa de inclusão em sua contradição com o modo de produção capitalista e a premissa da conquista da igualdade pela independência. As feministas, especialmente mulheres com deficiência e cuidadoras de pessoas com deficiência chamaram a atenção para a questão do corpo, da dor, da subjetividade. Também discutiram a questão do cuidado e da interdependência como uma condição humana que não se limita às pessoas com alguma lesão (KITTAY, 1999), além de avançarem teoricamente apontando a transversalidade da deficiência em relação à gênero, geração, etnia (GARLAND-THOMPSON, 2002).

As teóricas feministas dos estudos sobre deficiência propuseram, ainda, o mergulho em questões pertinentes à esfera privada, uma vez que a questão da esfera pública estava bem demarcada pela primeira geração, que investiu em temas como o trabalho. Não se trata de uma mera inclusão de temas a esse campo científico, mas de um processo ideológico que confere visibilidade para uma experiência de opressão cultural e historicamente ocultada (GARLAND-THOMPSON, 2002). Além disso, também retomaram a experiência do corpo deficiente, o que havia sido afastado pela tentativa de desessencializar a deficiência e situá-la no contexto (DINIZ, 2007; SHAKESPEARE, 1998). Há, portanto, nesse segundo momento dos estudos sobre deficiência, uma retomada do corpo, da dor, da lesão, mas com um enfoque marcadamente construcionista.

Em realidade, o potencial de articulação do campo teórico feminista e com estudos sobre deficiência é tanto maior quanto mais se defenda: 1) o pressuposto da desnaturalização do corpo, 2) a dimensão identitária do corpo e 3) a ética feminista da deficiência e do cuidado (MORRIS, 1996; MAYS, 2006; MELLO; NUERNBERG, 2012). Nesse sentido, essa articulação é tão importante para o campo feminista e de gênero quanto para a produção do conhecimento sobre deficiência no âmbito das ciências humanas.

Ademais, essa perspectiva da segunda geração dos estudos sobre deficiência nos interessa aqui em razão de seu potencial para análise de produções culturais destas pessoas, como é o caso dos conteúdos "postados" pelos "blogueiros" com deficiência. Suas postagens abrangem textos temáticos, relatos de experiência, informações e conteúdos pessoais que precisam ser analisados tanto como modos de resistência aos processos de exclusão impostos por uma sociedade normocêntrica, quanto como modos de subjetivação que revelam a 
possibilidade de se situar a deficiência como uma categoria identitária, articulada com gênero, geração, classe, etnia, religião e orientação sexual.

\section{Método}

É inegável o crescente uso do computador e da Internet no cotidiano da vida contemporânea. Tal prática sedimenta-se como criadora de novos arranjos relacionais nas últimas décadas. Esta nova tecnologia traz, embutidas, não apenas inéditas possibilidades de sociabilidade, modos de representação e comunicação, mas, inclusive, provoca a rediscussão de um método de análise discursiva (LEWGOY, 2009).

Braga (2006) caracteriza o fazer etnográfico como uma descrição que se divide em dois níveis de densidade: superficial, relativo ao sentido de determinada ação e, densa, que é composta pela interpretação da rede de sentidos de determinado fenômeno. O objeto da etnografia reside, portanto, entre a descrição superficial e a densa. Conforme assinala a autora, compete, então, ao etnógrafo interpretar o fenômeno considerando suas múltiplas e complexas estruturas conceituais.

Partimos da análise de depoimentos de pessoas com deficiência, buscando situar a experiência da deficiência como uma forma de singularização. Para tanto, iniciamos nossa abordagem definindo a netnografia como método de análise. Esse termo deriva da técnica etnográfica cujo estudo é baseado na descrição de uma cultura ou comunidade ou apenas das características fundamentais destas. Portanto, a netnografia ${ }^{1}$ trata do estudo das práticas co-

\footnotetext{
1 Por sinal, uma das primeiras pessoas a usar metodologias de etnografia virtual foi uma pessoa com osteogênese imperfeita, a Antropóloga Rita Amaral do Núcleo de Antropologia Urbana da Universidade de São Paulo. Rita Amaral faleceu em 2011
}

municacionais entre diferentes grupos sociais mediadas pelo computador (MONTARDO; ROCHA, 2005).

De modo inaugural, em 1995, alguns autores americanos, tais como Bishop, Star, Neumann, Ignacio, Sandusky \& Schatz, definiram o neologismo "netnografia" como a preservação dos "detalhes ricos da observação em campo etnográfico usando o meio eletrônico para 'seguir seus atores'" (BRAGA, 2006, p. 4).

Segundo Montardo e Rocha (2005), o uso da netnografia como metodologia de pesquisa resulta da crescente expressão e complexidade das vivências da "sociedade digital". Vale salientar ainda que este método é bastante utilizado nas áreas de marketing, comunicação, antropologia e sociologia e que, dentre suas ferramentas de análise estão as cyberinterviews, o e-mail, os board posts (blogs), e os sites (AMARAL; NATAL; VIANA, 2008). Entretanto, utilizar este método de análise requer considerar que a comunicação mediada pelo computador configura-se por complexas atividades interligadas, nunca idênticas e que exigem a avaliação de aspectos contextuais (BRAGA, 2006).

Conforme Thompson (2006 apud MONTARDO; PASSERINO, 2006), o primeiro blog foi criado em 1997 por Justin Hall, nomeado de Links.net. Originalmente, os blogs eram filtros de conteúdo na Internet, bem como espaço para comentários sobre diversos assuntos. Atualmente, os blogs constituem um sistema para conteúdos/textos postados por pessoas e que são atualizados sistematicamente.

Para fins de exploração da realidade da deficiência como processo de natureza social e

por complicações respiratórias não passíveis de tratamento em função de seus impedimentos estruturais orgânicos. Isso é importante para esse artigo porque mostra que viver com deficiência também exigiu desta pesquisadora o uso de metodologias de pesquisa compatíveis com seu modo de vida e limitações físicas. 
cultural, foram selecionados 14 blogs, cujos autores retratam em seus textos, discursos que evidenciam sentidos sobre da vida com deficiência através de relatos de suas experiências e posicionamentos de natureza pessoal, ética e política.

Após a escolha dos blogs tendo como critério ter a vida com deficiência como enfoque principal, enviamos por e-mail uma carta-comunicado e um formulário com perguntas simples, tais como: nome, data de nascimento, causa e tipo de deficiência, e a opção de manter sigilo ou não sobre a sua identidade. Cabe mencionar que o envio de um termo de consentimento fez-se desnecessário por se tratar de uma análise de um conteúdo de caráter público.

Nos catorze blogs pesquisados, estão dispostos dezessete blogueiros, sendo importante apontar que um dos blogs desta pesquisa é mantido por cinco pessoas, quatro delas com deficiência. No levantamento de dados dos pesquisados foi possível constatar que dez são mulheres e sete, homens. Oito são do Estado de São Paulo, três são do Rio de Janeiro, duas são do Rio Grande do Sul, dois são de Minas Gerais e apenas um é do Mato Grosso do Sul e outra é de Santa Catarina. Quanto à faixa etária dos blogueiros, catorze estão entre 30 e 38 anos; um possui 42, outra 48 e um, 56 anos.

Em relação ao tipo de deficiência, quinze são cadeirantes, dentre os quais dois são tetraplégicos - um por acidente de carro e um por ter contraído o vírus da poliomielite; sete tornaram-se paraplégicos por acidente de carro, um por acidente de moto, um por arma de fogo e três também em decorrência do vírus da poliomielite. Apenas uma das pessoas pesquisadas tornou-se deficiente (cadeirante) por acometimento congênito, devido à paraparesia progressiva (paralisia incompleta de nervo ou músculo dos membros inferiores que não perderam inteiramente a sensibilidade e o movimento). Uma das pesquisadas tornou-se deficiente auditiva por sequela de caxumba e uma tornou-se deficiente visual por acidente com arma de fogo. Entre todos os blogueiros que responderam à carta-comunicado, foi unânime a opção de não manter o sigilo sobre sua identidade nesta pesquisa.

Abaixo segue uma tabela descritiva com alguns dos dados que caracterizam os blogs e seus mantenedores.

Tabela 1: Descrição dos blogs e autores, conforme gênero, idade, tipo de deficiência e cidade.

\begin{tabular}{|c|c|c|c|c|c|c|}
\hline $\begin{array}{l}\text { Autor } \\
\text { (a/es) }\end{array}$ & \begin{tabular}{|c|} 
Se- \\
xo
\end{tabular} & $\begin{array}{c}\text { Ida- } \\
\text { de }\end{array}$ & Blog & Link & \begin{tabular}{|c|} 
Tipo \\
de De- \\
ficiên- \\
cia \\
\end{tabular} & $\begin{array}{c}\text { Ci- } \\
\text { dade }\end{array}$ \\
\hline $\begin{array}{l}\text { Adriana } \\
\text { Lage }\end{array}$ & $F$ & 35 & $\begin{array}{c}\text { Adriana } \\
\text { Lage }\end{array}$ & $\begin{array}{c}\text { www. } \\
\text { saci.org. } \\
\text { br }\end{array}$ & \begin{tabular}{|l|} 
Física \\
- Tet- \\
raple- \\
gia
\end{tabular} & \begin{tabular}{|l} 
Belo \\
Hori- \\
zonte/ \\
MG \\
\end{tabular} \\
\hline $\begin{array}{l}\text { Aldrey } \\
\text { Laufer }\end{array}$ & $F$ & 42 & $\begin{array}{l}\text { Vida } \\
\text { Sobre } \\
\text { Rodas }\end{array}$ & $\begin{array}{c}\text { aldrey- } \\
\text { laufer. } \\
\text { blogspot. } \\
\text { com }\end{array}$ & $\begin{array}{l}\text { Física } \\
\text { - Para- } \\
\text { plegia }\end{array}$ & \begin{tabular}{|l} 
Porto \\
Alegre/ \\
RS
\end{tabular} \\
\hline $\begin{array}{l}\text { Alessan- } \\
\text { dro Fer- } \\
\text { nandes }\end{array}$ & $M$ & 38 & $\begin{array}{l}\text { Blog do } \\
\text { Cadei- } \\
\text { rante }\end{array}$ & \begin{tabular}{|c} 
blogdoca- \\
deirante. \\
blogspot. \\
com
\end{tabular} & \begin{tabular}{|l|} 
Física \\
- Para- \\
plegia
\end{tabular} & \begin{tabular}{|l|} 
Belo \\
Hori- \\
zonte/ \\
MG \\
\end{tabular} \\
\hline $\begin{array}{c}\text { Chris- } \\
\text { tian } \\
\text { Matsuy, } \\
\text { Cris } \\
\text { Costa, } \\
\text { Eduardo } \\
\text { Camara, } \\
\text { Nickolas } \\
\text { Marcon }\end{array}$ & $\begin{array}{c}\text { M, } \\
F_{\prime} \\
M, \\
M\end{array}$ & $\begin{array}{l}37, \\
32, \\
34, \\
38\end{array}$ & $\begin{array}{l}\text { Blog Mão } \\
\text { na Roda }\end{array}$ & $\begin{array}{l}\text { maonar- } \\
\text { odablog. } \\
\text { com.br }\end{array}$ & \begin{tabular}{|l|} 
Física \\
- todos \\
com \\
para- \\
plegia
\end{tabular} & $\begin{array}{l}\text { São } \\
\text { Paulo/ } \\
\text { SP, } \\
\text { Rio de } \\
\text { Janei- } \\
\text { ro/RJ, } \\
\text { Rio de } \\
\text { Janei- } \\
\text { ro/RJ, } \\
\text { Rio de } \\
\text { Janei- } \\
\text { ro/RJ }\end{array}$ \\
\hline $\begin{array}{l}\text { Evandro } \\
\text { Bonoc- } \\
\text { chi }\end{array}$ & $M$ & 36 & $\begin{array}{c}\text { Tocando } \\
\text { a Vida } \\
\text { Sobre } \\
\text { Rodas }\end{array}$ & $\begin{array}{c}\text { tocando- } \\
\text { avidaso- } \\
\text { brerodas. } \\
\text { blog } \\
\text { spot.com }\end{array}$ & \begin{tabular}{|l|} 
Física \\
- Para- \\
plegia
\end{tabular} & \begin{tabular}{|l|} 
São \\
José \\
dos \\
Cam- \\
pos/ \\
SP \\
\end{tabular} \\
\hline $\begin{array}{l}\text { Flávia } \\
\text { Cintra }\end{array}$ & $F$ & 37 & $\begin{array}{c}\text { Memórias } \\
\text { de Uma } \\
\text { Mãe Ca- } \\
\text { deirante }\end{array}$ & $\begin{array}{c}\text { maeca- } \\
\text { deirante. } \\
\text { com.br/ } \\
\text { blog }\end{array}$ & \begin{tabular}{|l|} 
Física \\
- Tet- \\
raple- \\
gia
\end{tabular} & \begin{tabular}{|l|} 
São \\
Paulo/ \\
SP
\end{tabular} \\
\hline
\end{tabular}




\begin{tabular}{|c|c|c|c|c|c|c|}
\hline $\begin{array}{c}\text { Jairo } \\
\text { Marques }\end{array}$ & $M$ & 37 & $\begin{array}{l}\text { Assim } \\
\text { Como } \\
\text { Você }\end{array}$ & $\begin{array}{c}\text { assimco- } \\
\text { movoce. } \\
\text { blog.uol. } \\
\text { com.br }\end{array}$ & $\begin{array}{l}\text { Física } \\
\text { - Para- } \\
\text { plegia }\end{array}$ & $\begin{array}{l}\text { São } \\
\text { Paulo/ } \\
\text { SP }\end{array}$ \\
\hline $\begin{array}{c}\text { Jucilene } \\
\text { Braga }\end{array}$ & $F$ & 33 & $\begin{array}{c}\text { Jucilene } \\
\text { Braga }\end{array}$ & \begin{tabular}{|c|} 
www. \\
dormvirt. \\
com.br/ju
\end{tabular} & Visual & $\begin{array}{l}\text { São } \\
\text { Paulo/ } \\
\text { SP }\end{array}$ \\
\hline $\begin{array}{l}\text { Juliana } \\
\text { Carv- } \\
\text { alho }\end{array}$ & $F$ & 30 & $\begin{array}{c}\text { Comédias } \\
\text { da Vida } \\
\text { Aleijada }\end{array}$ & \begin{tabular}{|l|} 
come- \\
diasda- \\
vidaa- \\
leijada. \\
blogspot. \\
com
\end{tabular} & $\begin{array}{l}\text { Física } \\
\text { - Para- } \\
\text { plegia }\end{array}$ & $\begin{array}{l}\text { Porto } \\
\text { Alegre/ } \\
\text { RS }\end{array}$ \\
\hline $\begin{array}{l}\text { Lakshmi } \\
\text { Lobato }\end{array}$ & $\mathrm{F}$ & 35 & $\begin{array}{l}\text { Desculpe, } \\
\text { Não Ouvi! }\end{array}$ & \begin{tabular}{|c|} 
descul- \\
penao- \\
ouvi. \\
laklobato. \\
com \\
\end{tabular} & $\begin{array}{l}\text { Audi- } \\
\text { tiva }\end{array}$ & $\begin{array}{l}\text { São } \\
\text { Paulo/ } \\
\text { SP }\end{array}$ \\
\hline $\begin{array}{c}\text { Ronaldo } \\
\text { Capar- } \\
\text { roz } \\
\text { Garcia }\end{array}$ & $M$ & 56 & $\begin{array}{l}\text { Rodas da } \\
\text { Liberdade }\end{array}$ & $\begin{array}{c}\text { blogro- } \\
\text { daseliber- } \\
\text { dade. } \\
\text { blogspot. } \\
\text { com }\end{array}$ & $\begin{array}{l}\text { Física } \\
\text { - Para- } \\
\text { plegia }\end{array}$ & $\begin{array}{l}\text { São } \\
\text { Paulo/ } \\
\text { SP }\end{array}$ \\
\hline $\begin{array}{l}\text { Tabata } \\
\text { Contri }\end{array}$ & $F$ & 30 & $\begin{array}{l}\text { Tocando } \\
\text { as Rodas }\end{array}$ & $\begin{array}{c}\text { tocando- } \\
\text { asrodas. } \\
\text { blogspot. } \\
\text { com }\end{array}$ & $\begin{array}{l}\text { Física } \\
\text { - Para- } \\
\text { plegia }\end{array}$ & $\begin{array}{l}\text { São } \\
\text { Paulo/ } \\
\text { SP }\end{array}$ \\
\hline $\begin{array}{l}\text { Tuigue } \\
\text { Venzon }\end{array}$ & $\mathrm{F}$ & 31 & $\begin{array}{c}\text { Muletas } \\
\text { Cor-de- } \\
\text { rosa }\end{array}$ & $\begin{array}{c}\text { mule- } \\
\text { tascor- } \\
\text { derosa. } \\
\text { blogspot. } \\
\text { com }\end{array}$ & \begin{tabular}{|l|} 
Física \\
- Para- \\
paresia
\end{tabular} & $\begin{array}{l}\text { Tiju- } \\
\text { cas/SC }\end{array}$ \\
\hline
\end{tabular}

Fonte: Dados disponibilizados pelos blogueiros na descrição do perfil do mantenedor.

\section{Análises e discussão}

No intuito de facilitar a análise qualitativa desta pesquisa ${ }^{2}$, elencamos três categorias importantes que demonstram assuntos pertinentes em todos os blogs e que condizem com as teorias utilizadas na seguinte discussão. A eleição das categorias de análise se deu a partir de exaustiva leitura do conteúdo de todos os blogs, disponível na internet no período de 20 de janeiro a 10 de maio de 2012, buscando encontrar pontos de interseção e coincidência

\footnotetext{
${ }^{2}$ Agradecemos aos revisores anônimos pelas cuidadosas observações, que muito colaboraram para maior qualidade desse texto.
}

de temas e também de formas de abordá-los. Para tanto, apoiamo-nos em referências como Herrera e Passerino (2008) e Passerino (2011), que compartilham do uso do método netnografia na análise de fenômenos sociais, propondo a eleição de categorias de análise por meio da imersão nos dados e observações, os quais foram permanentemente analisados com base no modelo social da deficiência.

\subsection{0 humor}

O humor tem sido cada vez mais analisado nas ciências humanas, tanto em seu potencial transgressivo como em seu lugar na perpetuação de práticas e discursos sexistas e racistas (DAHIA, 2008). Da linguística à psicanálise, o humor se apresenta como um objeto multifacetado que abre perspectivas para a análise sociocultural e psicológica das trocas sociais (ALBERTI, 1999). Nesse tópico, interessa-nos destacar o efeito transgressivo do humor ao deslocar a deficiência desde o universo biomédico para a esfera do cotidiano.

Numa primeira análise dos blogs, procurando encontrar neles alguma unidade, destaca-se o teor cômico da condução dos textos postados, por meio de relatos que conduzem o leitor ao riso e à ironia frente a situações comumente vividas pelas pessoas com deficiência, especialmente no tocante às barreiras físicas enfrentadas por elas no cotidiano. Muitas dessas situações envolvem acidentes, quedas, mas também são bem comuns relatos sobre o modo como os não deficientes percebem a realidade da deficiência.

Um dos blogueiros pesquisados, Jairo Marques, autor do blog "Assim Como Você", diz na postagem "Ahh, o calor": "Os 'minino' sorteados com esclerose múltipla (aquela que vai 
arruinando a musculatura do povo de golim em golim). [...] que tempo máximo é possível, para cada tipo de 'malacabação', ficar de papo para o ar no sol" (MARQUES, 2012a). Outra blogueira, Juliana Carvalho, que é paraplégica e autora do blog "Comédias da Vida Aleijada", na postagem "Calça saruel é terapia assistiva" brinca com a falta de sensibilidade para perceber a hora de ir ao banheiro: "Tô no salão, bem bela me arrumando pra gravar. Dá aquela 'vontade' de fazer pipi. Vontade entre aspas mesmo porque quebrado em geral não sente essa vontade" (CARVALHO, 2011a).

Na primeira postagem acima, percebemos que o autor define como "sorteado" aquele que possui esclerose múltipla. É importante mencionar que "sortear" significa "eleger por sorte", o que nos remete a uma idéia contrária à anormalidade o fato de possuir tal condição. Posteriormente, ainda no primeiro trecho, o autor utiliza termos bastante informais e engraçados ("arruinando" e "de golim em golim") para informar que a esclerose múltipla trate-se de uma doença degenerativa. Na segunda postagem citada, vemos que a autora nomeia "paraplégico" como "quebrado" e relata, com ironia, o fato de os paraplégicos não sentirem vontade de ir ao banheiro.

Essa forma de narrar a vida das pessoas com deficiência pode ser analisada como uma oposição direta à perspectiva da deficiência como "tragédia pessoal", que caracteriza o modelo biomédico da deficiência. De fato, os avanços médicos garantiram (e garantem) significativas melhorias no bem-estar de deficientes e não-deficientes. Entretanto, a afirmativa da deficiência como uma variação da espécie humana e, portanto, como um modo de vida, deve-se principalmente a uma questão "ética que desafia nossos padrões de normal e patológico" (DINIZ, 2007, p. 9).
Convergindo a noção de deficiência como uma maneira de perceber o mundo à capacidade dos meios de comunicação para disseminar informação, Amaral (1995) ressalta que estes meios possuem o poder de contribuir para transformar o diferente em familiar para o público. É neste contexto que o humor torna-se uma ferramenta importante para romper o incômodo do desconhecido.

\subsection{Afetividade e sexualidade}

Outro tema recorrente entre as postagens dos blogueiros e blogueiras com deficiência é a sexualidade, assunto sempre polêmico nesse contexto em razão dos preconceitos e tabus que o cercam. É vasta a literatura que investiga a questão da sexualidade e afetividade na deficiência (SHAKESPEARE, 1998; 2007; MAIA, 2006), onde geralmente se ressalta a histórica interdição da sexualidade da pessoa com deficiência, que na maior parte das vezes tem cerceados seus direitos sexuais e reprodutivos, além de ser infantilizada e submetida a diversas outras formas de preconceito (TEPPER, 2000; GESSER; NUERNBERG, 2012).

Um exemplo das postagens dos blogs sobre esse tema é o trecho do texto "Comédia da vida aleijada - a saga" de Juliana Carvalho: "Tá, a maioria deve estar se perguntando 'mas o pinto do aleijado'? Funciona. Aleijado faz o que todo mundo faz, só que às vezes de modo um pouco diferente" (CARVALHO, 2011b). Esse tipo de narrativa que gera o efeito de dissolução de mitos nessa esfera da intimidade e sexualidade da pessoa com deficiência também se estende aos direitos reprodutivos, como podemos ver na postagem "Carta ao Jairo" de Flávia Cintra, autora do blog "Memórias de uma Mãe Cadeirante", a seguir: 
"O dia mais feliz da minha vida foi o do nascimento do Mateus e da Mariana. Fiquei grávida sem planejar, depois dos 30, tetraplégica e de gêmeos. Minha gravidez 'de alto risco' foi um período saudável, tranquilo, emocionante e inesquecível. Eu amava minha barriga cada vez mais redonda e as sensações de ter meus bebês crescendo, se mexendo, se preparando para virem ao mundo" (CINTRA, 2010).

Há ainda aqueles blogueiros como Márcia Gori que dão especial atenção à questão da sexualidade, entrando inclusive em temas ainda mais polêmicos como a relação das pessoas com deficiência com os devotees ${ }^{3}$ (GORI, 2012). Mantido por uma militante feminista com deficiência, o blog "Márcia Gori - Sou um Pássaro de Fogo" é um dos que mais se empenham em explorar esse tema, também compartilhando publicamente experiências pessoais que problematizam o discurso medicalizante em torno da sexualidade na deficiência e enfocando diversos temas relativos aos direitos humanos.

Um primeiro aspecto a se destacar aqui na tentativa de análise do teor e conteúdo destas postagens é o fato de seguirem a premissa originalmente proposta pelo feminismo de tornar públicos aspectos e vivências da vida íntima e privada como estratégia para gerar transformações políticas importantes para os avanços dos direitos sexuais e reprodutivos das pessoas com deficiência (OKIN, 2008). Ao seguirem o slogan "o pessoal é político", fazendo os leitores pensarem e problematizarem os mitos em torno da sexualidade das pessoas com deficiência ou encorajarem outras pessoas com deficiência a viverem seus

\footnotetext{
${ }^{3}$ Devotees são pessoas, a maior parte do sexo masculino que manifestam um especial interesse sexual por pessoas com alguma lesão ou incapacidade, especialmente por pessoas com alguma amputação (BRUNO, 1997).
}

direitos sexuais e reprodutivos, tais postagens difundem uma perspectiva emancipatória que retira do corpo e joga para as barreiras sociais as limitações impostas para o exercício da vida sexual, afetiva e reprodutiva (SHAKESPEARE, 1998, 2007).

Cumpre ressaltar, contudo, que não se está afirmando aqui uma perspectiva normatizante da sexualidade das pessoas com deficiência, impondo a elas expectativas que negam ou omitem a realidade de sua variação corporal e social. Não desejamos negar a presença dos impedimentos físicos comuns, como a incontinência urinária, as restrições de mobilidade ou a ausência de sensibilidade tátil (SOARES et al, 2008). Aliás, algumas postagens explicitam justamente como os homens e mulheres com deficiência lidam com estes impedimentos em suas relações afetivas e sexuais, como na postagem intitulada "Amor em dobro" de Alessandro Fernandes, autor do "Blog do Cadeirante", a seguir:

Nem tudo é possível e muito menos fácil na vida a dois. A pessoa tem que entender que a limitação não é só de locomoção. A incontinência urinária, pra mim, é uma das coisas que mais incomoda. [...] Pode ser chato, inconveniente e até causar vergonha, mas a culpa não é nossa. Aí entra a compreensão, e a mulher se coloca numa situação quase de mãe, tem que enxugar, limpar, trocar a roupa, do jeito que fazemos com bebês. E ainda é preciso ajudar para se vestir, calçar sapatos e desmontar e montar a cadeira de rodas toda vez que sair de carro. Do nosso ponto de vista, chegamos a um grau de intimidade que jamais imaginamos. E sabemos dar valor a isso (FERNANDES, 2012a).

Nesse sentido, chamamos a atenção para a importância da visibilidade da experiência da deficiência no contexto da sexualidade e inti- 
midade. Dessa postagem, portanto, extraímos não a abordagem que se pautando pela lógica medicalizante, enfoca a fragilidade e limitação da pessoa com deficiência, mas buscamos ressaltar a expansão que a experiência da deficiência proporciona à definição de sexualidade por meio de suas implicações práticas, sociais e culturais (SHAKESPEARE, 2007; SAKELLARIOU, 2011). Nesse sentido, ao invés de conduzirmos nossa análise para o deslocamento destas experiências para o contexto do desvio, desejamos atentar para a importância da abertura e o acolhimento destas diferenças como possibilidades de exercício da sexualidade e como modalidades legítimas de vivência da intimidade inseridas na condição humana.

\subsection{Informação e direitos humanos}

Como terceira e última categoria a ser analisada, escolhemos discutir informações que são divulgadas pelos(as) blogueiros(as) e que possuem um efeito de fortalecer a identidade coletiva como pessoas com deficiência. Esta categoria, talvez a mais importante delas - e pré-requisito para todas as outras, visa destacar o modo como as pessoas com deficiência estão assumindo a postura de sujeitos sociais. Não abordam somente os benefícios e o respeito às leis, mas também fomentam o diálogo a respeito do direito de ser pessoa com limites e potencialidades, ou seja, ter autonomia e "participação ativa na vida" (AMARAL, 1995, p. 191).

Ilustramos esta colocação citando o blogueiro Alessandro Fernandes, quando diz no texto "Inclusão dá trabalho", a respeito da Lei de Cotas:

As empresas privadas geralmente contratam deficientes só para cumprir a lei 8.213/91, que estabelece que empresa com mais de 100 funcionários deve preencher uma porcentagem do seu quadro de pessoal com pessoas com deficiência. E como é só para cumprir a lei mesmo, geralmente colocam os deficientes em cargos inferiores, com baixa complexidade e baixos salários. Quando vejo isso, me parece mais caridade do que contratação de uma pessoa com potencial de crescer e contribuir para a empresa como qualquer outro funcionário (FERNANDES, 2012).

Ainda a respeito do mercado de trabalho, Jairo Marques escreve na postagem intitulada "Os coitadinhos": "Quero que meu colega de trabalho me veja como alguém para colaborar e não para me encostar numa empresa, quero ser visto como alguém com potencial para fazer o que eu bem entender... Quero ser retrato como 'serumano' capaz dentro de minhas limitações" (MARQUES, 2012b).

Nota-se que esses trechos afirmam que, na prática, a pessoa com deficiência possui a qualidade de cidadã, mas, em contrapartida, é sublinhada a necessidade do reconhecimento das potencialidades da pessoa com deficiência para exercer qualquer função no trabalho, por exemplo. A ideia transmitida pelos blogueiros afirma que além do cumprimento literal de uma lei, é fundamental garantir ao sujeito com deficiência o estado de cidadão, de sujeito capaz e produtivo. Isso porque as pessoas com deficiência possuem direitos universais reconhecidos, porém, uma visão ainda estereotipada, impede o pleno usufruto desses direitos (AMARAL, 1995).

Para explorarmos ainda mais essa postura de sujeitos sociais, podemos citar a fala de Jairo Marques ainda no texto "Os coitadinhos":

Meu povo, quando mais se acentuam nas pessoas com deficiência características de 'coitadismo' mais distantes elas ficam de serem cidadãos com direitos e deveres e mais pró- 
ximas ficam de ser 'necessitados especiais' e alheios ao cotidiano, ao todo. [...] Tá passando da hora de a gente exigir e tentar direcionar melhor essa exploração intensa da imagem da deficiência. Mostrar que com mais cidadania, todo mundo vai viver melhor, mais harmoniosamente e menos capenga, menos dependente e 'sofredora'! (MARQUES, 2012b).

Não apenas neste trecho, mas em todos os blogs pesquisados, percebemos que os blogueiros promovem uma rediscussão acerca de uma visão pré-concebida da deficiência, que previa uma interpretação mágico-religiosa, biológica-explicativa ou intervencionista. Neste novo discurso, os blogueiros abolem à condição de baixo controle, dependência e falta de autonomia pessoal (DÍAZ, 2007). Para Amaral (1995), isto significa não atribuir somente ao aparato público a responsabilidade de garantia de leis e a efetiva inclusão do deficiente, mas sim a todas as pessoas.

Esta noção de identidade como um posicionamento relacional, identificada nos blogs, representa uma fonte importante de reflexão sobre a identidade coletiva que se forma através do compartilhamento de experiências e divulgação de informações e leis, "pois esta dimensão narrativa, simbólica da identidade, [...] adquire um sentido na interdiscursividade no fenômeno da deficiência.". Portanto, esta prática de "homens que atuam e falam uns para os outros" tem o efeito de converter experiências individuais em coletivas (DÍAZ, 2007, p. 88-89).

A concepção de pessoa com deficiência como "um de nós" e não como um "outro" que encarna o desvio, depende de uma profunda revisão das formas hegemônicas de pensar o que é o humano. Em relação a isso, de modo explicativo e casual, a blogueira Juliana CarvaIho nos instiga no texto "Programação do Seminário":
Sim, porque a tão esperada e desejada inclusão que nós queremos depende essencialmente de uma profunda mudança cultural. E a construção dessa "rampa" na cabeça das pessoas pode ser bem mais rápida com o apoio da mídia. Ações de marketing social em novelas e filmes mostraram seu poder nos últimos anos. A imprensa também tem seu papel ao quebrar preconceitos através da informação e ao mostrar uma imagem positiva das pessoas com deficiência. Acessibilidade aos meios de comunicação é outro ponto fundamental para a inclusão. Como ter pessoas cegas e surdas cidadãs se elas não têm acesso à informação?! Os recursos que permitem o acesso à informação são lei no Brasil. Além de permitirem a plena participação, eles aumentam o sentimento de representação (CARVALHO, 2012).

Vemos, então, que esses discursos negam a condição da pessoa com deficiência como "pessoa afetada", ainda mais que tais sujeitos assumem explicitamente o lugar de narradoras da própria condição e vida (DÍAZ, 2007). Nesse sentido, a divulgação de informações sobre leis e conquistas políticas para as pessoas com deficiência cumpre o papel de aglutinar interesses políticos e produz o efeito de engendrar por meio da experiência da deficiência, uma forma de identificar-se no mundo das trocas sociais.

\section{Considerações finais}

Ao mergulharmos nos conteúdos dos blogs, buscando encontrar neles pontos centrais de reflexão e análise, deparamo-nos com evidências de que há uma rede social bem consolidada por trás da coincidência de temas e perspectivas políticas. Não apenas cada blogueiro(a) sugere ao internauta explorar links que remetem a outros blogs de colegas blogueiros 
com deficiência, como também nas próprias postagens citam uns aos outros e a outras esferas dos movimentos sociais de pessoas com deficiência. Isso, somado ao que já expomos anteriormente, permite avaliar as narrativas analisadas e essas modalidades de intercâmbio de informação na internet como indícios da formação de uma "rede de movimento social", conceito que, conforme Scherer-Warren (2006):

[...] pressupõe a identificação de sujeitos coletivos em torno de valores, objetivos ou projetos em comum, os quais definem os atores ou situações sistêmicas antagônicas que devem ser combatidas e transformadas. Em outras palavras, o Movimento Social, em sentido mais amplo, se constitui em torno de uma identidade ou identificação, da definição de adversários ou opositores e de um projeto ou utopia, num contínuo processo em construção e resulta das múltiplas articulações acima mencionadas. A ideia de rede de movimento social é, portanto, um conceito de referência que busca apreender o porvir ou o rumo das ações de movimento, transcendendo as experiências empíricas, concretas, datadas, localizadas dos sujeitos/atores coletivos (SCHERER-WARREN, 2006, p. 113).

Esse processo espelha o fato de que no mundo contemporâneo, os movimentos sociais cada vez mais se articulam em torno de identidades, valores e dimensões do sujeito concreto (PIERUCCI, 1998; SCHERER-WARREN, 2006). Os feminismos, as lutas motivadas por questões étnico-raciais e os movimentos rurais são exemplos de formas de ativismo estreitamente vinculadas à formação de novas identidades e que remetem a características sociais consti- tuintes dos sujeitos. Contudo, a partir de Lago (1999), acreditamos que não se trata de supor a "fragmentação" da identidade, como sustentam autores como Hall (2006), uma vez que as dimensões coletivas e pessoais da identidade são mutuamente constitutivas, mantendo alguma coerência subjetiva entre si.

Apresentar a deficiência como um modo de vida e não como uma "tragédia pessoal" ou condição desviante (DINIZ, 2007), relatando de forma criativa situações do cotidiano de quem vive com deficiência, é parte desse processo de produção de uma identidade coletiva e pessoal como pessoa com deficiência, gerando o efeito da mobilização deste grupo em torno de sua condição de desigualdade social e da afirmação da legitimidade de se viver no contexto produzido nessa variação corporal.

Nesse trabalho evidenciamos a emergência de novas narrativas sobre a deficiência na internet que fogem à lógica medicalizante sobre essa condição e buscam dar visibilidade às barreiras sociais que incidem sobre a vida das pessoas que possuem impedimentos ou lesões de natureza física. Isso é feito por meio de discursos que relacionam ideias, fatos e vivências que surpreendem por revelar aos leitores-internautas um modo de viver com deficiência que não se encerra na própria lesão e que é indissociável do contexto de vida de cada sujeito. Isto posto, consideramos ser fundamental avançar na direção de modelos teóricos sobre esse tema que permitam abranger a complexidade destes processos e situar a deficiência como um processo multideterminado e singularmente vivido. 


\section{Referências}

ALBERTI, V. O riso e o risível: na historia do pensamento. Rio de Janeiro: Ed. Jorge Zahar, 1999.

AMARAL, L. A. Conhecendo a Deficiência (em companhia de Hércules). São Paulo: Robe, 1995, 204p.

AMARAL, A.; NATAL, G. ; VIANA, L. Netnografia como aporte metodológico da pesquisa em comunicação digital. Comunicação cibernética, Famecos/PUCRS, n. 20, p. 34-40, dez-2008.

BARNeS, C.; OlIVER, M.; BARTON, L. Disability Studies Today. Cambridge: Polity Press, 2008.

BRAGA, A. Técnica etnográfica aplicada à comunicação online: uma discussão metodológica. UNIrevista, São Leopoldo, v. 1, n. 3, 2006.

BRUNO, R. Devotees, Pretenders and Wannabes: Two Cases of Factitious Disability Disorder. Sexuality and Disability, v. 15, n. 4, p. 243-260, 1997.

CARVALHO, J. Programação de Seminário. 18 jul. 2011. Comédias da Vida Aleijada. Disponível em: <http://comediasdavidaaleijada.blogspot.com.br/2011/07/programacao-do-seminario.html>. Acesso em: 3 fev. 2012.

Calça saruel é terapia assistiva. 11 mai. 2011. Comédias da Vida Aleijada. Disponível em: <http://comediasdavidaaleijada.blogspot.com.br/2011/05/calca-saruel-e-tecnologia-assistiva.html>. Acesso em: 13 dez. 2011 a.

. Comédia da vida aleijada - a saga. 15 dez. 2008. Comédias da Vida Aleijada. Disponível em: < http://comediasdavidaaleijada.blogspot.com.br/2008/12/comdia-da-vida-aleijada-saga.html>. Acesso em: 28 nov. 2011b.

CINTRA, F. Carta ao Jairo. 13 nov. 2010. Memórias de uma Mãe Cadeirante. Disponível em: <http:// maecadeirante.com.br/blog >. Acesso em: 25 nov. 2010.

DAHIA, S. L. M. A mediação do riso na expressão e consolidação do racismo no Brasil. Sociedade e Estado, v. 23, n. 3, 2008, p. 697-720.

DÍAZ, K. G. Discapacidad y Procesos Identitarios. Revista Ciencias de la Salud, Bogotá, v. 5, n. 2, p. 86-91, 2007. 
DINIZ, D. Deficiência e Discriminação. Brasília: Letras Livres, 2010, 288p.

. O que é deficiência? São Paulo: Brasiliense, 2007, 79p.

.; MEDEIROS, M.; BARBOSA, L. Deficiência e Igualdade. Brasília: Letras Livres, 2010, 248p.

FERNANDES, A. Amor em dobro. 12 jun. 2009. Blog do Cadeirante. Disponível em: < http://blogdocadeirante.blogspot.com.br/2009/06/amor-em-dobro.html>. Acesso em: 15 jan. 2012a.

Inclusão dá trabalho. 24 jan. 2012. Blog do Cadeirante. Disponível em: < http://blogdocadeirante.blogspot.com.br/2012/01/inclusao-da-trabalho.html>. Acesso em: 26 jan. 2012b.

GARLAND-THOMSON, R. Integrating Disability, Transforming Feminist Theory, NWSA Journal, v. 14, $\mathrm{n}$. 3, 2002, p. 1-32.

GESSER, M.; NUERNBERG, A. H. Gênero, Direitos Humanos e Cidadania: a Psicologia contribuindo para a ressignificação da experiência da deficiência em mulheres de camadas populares. Prêmio Profissional: "Democracia e Cidadania Plena das Mulheres". Brasília. Conselho Federal de Psicologia, 2012.

GORI, M. Márcia Gori - Sou um Pássaro de Fogo. Disponível em: <http://mrciagori.blogspot.com>. Acesso em: 25 abr. 2012.

HALL, S. A identidade cultural na pós-modernidade. 11. ed. Rio de Janeiro: DP\&A Editora, 2006.

HERRERA, M. H.; PASSERINO, L. M. Estigma e ciberespaço: desafios da netnografia como metodologia para pesquisa de redes temáticas na blogosfera. Revista RENOTE: Novas Tecnologias na Educação, v. 6, n. 2. 2008. s/p.

KITTAY, E. F. Love's Labor: essays on women, equality and dependency. New York: Routledge, 1999.

LEVIN ROJO, E.; ESPINOZA, M. D. Enunciar(se) desde la discapacidad. Argumentos, n. 22, p. 141-156, 2009.

LEWGOY, B. A invenção da (ciber)cultura. Virtualização, aura e práticas etnográficas pós-tradicionais no ciberespaço. Civitas Revista de Ciências Sociais. Pontifícia Universidade Católica do Rio Grande do Sul, v. 9, n. 2, p. 185-196, 2009.

LOBO, L. F. Infames da História - pobres, escravos e deficientes no Brasil. Rio de Janeiro: Lamparina, 2008. 
MAIA, A. C. B. Sexualidade e Deficiências. São Paulo: Unesp, 2006.

MARQUES, J. Ahh, o calor. 23 jan. 2012. Assim Como Você. Disponível em: < http://assimcomovoce. folha.blog.uol.com.br/>. Acesso em: 28 jan. 2012a.

Os coitadinhos. 2 mai. 2012. Assim Como Você. Disponível em: < http://assimcomovoce.blogfolha.uol.com.br/2012/05/02/os-coitadinhos/>. Acesso em: 3 mai. 2012b.

MAYS, Jennifer M. "Feminist Disability Theory: domestic violence against women with a disability". Disability \& Society. V. 21, n. 2, 2006, p. 147-158.

MELLO, A. G.; NUERNBERG, A. H. Gênero e Deficiência: interseções e perspectivas. Revista Estudos Feministas, 2012. (no prelo)

MONTARDO, S. P.; PASSERINO, L. Estudo dos blogs a partir da netnografia: possibilidades e limitações. RENOTE: Revista Novas Tecnologias na Educação, v. 4, 2006.

MONTARDO, S. P.; ROCHA, P. J. Netnografia. Incursões metodológicas na cibercultura. Revista E-compós, Brasilia, v. 4, 2005. Disponível em: <http://boston.braslink.com/compos.org.br/e\%2Dcompos/ adm/documentos/dezembro2005_paula_sandra.pdf>. Acesso em: 2 ago. 2007.

MORRIS, J. Encounters with Strangers: feminism and disability. London: The Women's Press, 1996.

OKIN, S. M. O Gênero, o público e o privado. Estudos Feministas, Florianópolis, 2008. p. 305-332.

OLKIN, R. What Psychoterapists Should Know About Disability. Nova York: The Guilford Press, 2009.

PIERUCCI, A. Ciladas da Diferença. São Paulo: Editora 34, 1998.

SAKELLARIOU, D. Sexuality and Disability: a discussion on care of the self. Sexuality and Disability. Cardiff: University of Cardiff, 2011. 11p.

SHAKESPEARE, T. Disability, Normality, and Difference: psychological challenges in obstetrics and gynecology. Editado por Jayne Cockburn e Michael Pawson. Londres: Spriger, 2007, p. 51-59.

. Poder y Prejuicio: los temas de género, sexualidad y discapacidad. In: Discapacidad Y Sociedad. Editado por Len Barton. Madrid: Ediciones Morata, 1998, p. 205-229.

SHERER-WARREN, I. Das mobilizações às redes de movimentos sociais. Sociedade e Estado, Brasília, v. 21, n. 1, p. 109-130, jan./abr. 2006. Disponível em: <www.scielo.br/pdf/se/v21n1/v21n1a07.pdf>. 
Acesso em: 18 mai. 2012.

TEPPER, M. S. Sexuality and Disability: The Missing Discourse of Pleasure. Sexuality and Disability, v. 18, n. 4, 2000. p. 283-290.

Submetido para avaliação em 24 de outubro de 2012.

Aprovado para publicação em 27 de março de 2013.

\section{Karla Garcia Luiz}

Psicóloga e mestranda no Programa de Pós-Graduação em Psicologia da UFSC. Florianópolis/SC/Brasil. E-mail: karla. garcia.luiz@hotmail.com

\section{Adriano Henrique Nuernberg}

Doutor em Ciências Humanas e professor do Programa de Pós-Graduação em Psicologia da UFSC. Florianópolis/SC/ Brasil. E-mail: adrianoh@cfh.ufsc.br 